\title{
Histotype influences emergency presentation and prognosis in colon cancer surgery
}

Article in Langenbeck's Archives of Surgery · November 2019

DOI: 10.1007/s00423-019-01826-6

CITATIONS

2

11 authors, including:

Simone Sibio

Sapienza University of Rome

54 PUBLICATIONS 707 CITATIONS

SEE PROFILE

Vittoria Bellato

Policlinico Tor Vergata

17 PUBLICATIONS 28 CITATIONS

SEE PROFILE
READS

25

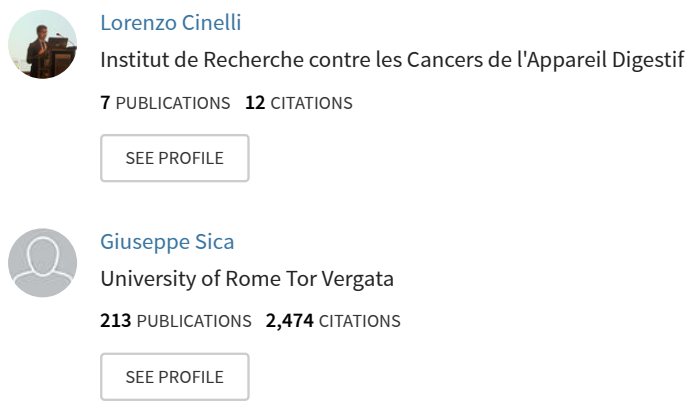

Some of the authors of this publication are also working on these related projects:

Peritoneal expression of Matrilysin helps identify early post-operative recurrence of colorectal cancer View project

Mo1702 Outpatient Anal Exploration and Fistula Treatment in Patients With Symptomatic Peri-Anal Crohn's Disease. Preliminary Report View project 


\section{Histotype influences emergency presentation and prognosis in colon cancer surgery}

\section{Simone Sibio, A. Di Giorgio, S. D’Ugo,}

G. Palmieri, L. Cinelli, V. Formica, B. Sensi, G. Bagaglini, S. Di Carlo, V. Bellato, et al.

Langenbeck's Archives of Surgery

ISSN 1435-2443

Langenbecks Arch Surg

DOI 10.1007/s00423-019-01826-6

\section{ONLINE FIRST}

Langenbeck's ARCHIVES OF SURGERY

founded in 1860

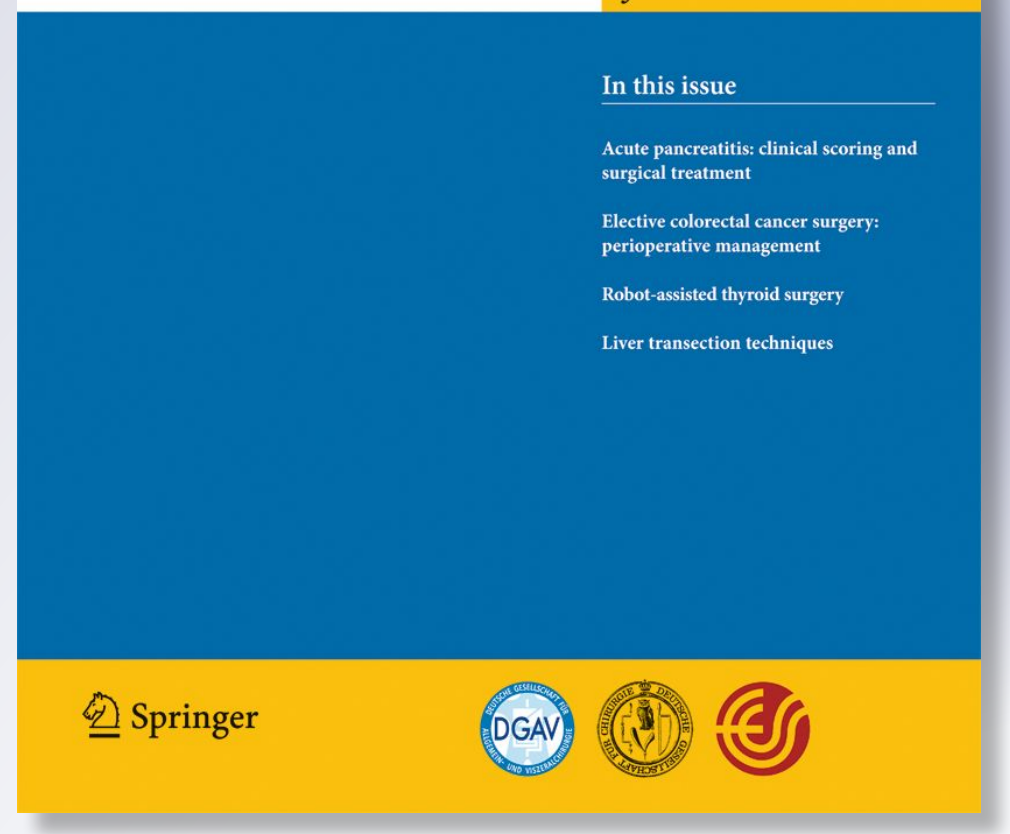

勿 Springer 
Your article is protected by copyright and all rights are held exclusively by SpringerVerlag GmbH Germany, part of Springer Nature. This e-offprint is for personal use only and shall not be self-archived in electronic repositories. If you wish to self-archive your article, please use the accepted manuscript version for posting on your own website. You may further deposit the accepted manuscript version in any repository, provided it is only made publicly available 12 months after official publication or later and provided acknowledgement is given to the original source of publication and a link is inserted to the published article on Springer's website. The link must be accompanied by the following text: "The final publication is available at link.springer.com". 


\title{
Histotype influences emergency presentation and prognosis in colon cancer surgery
}

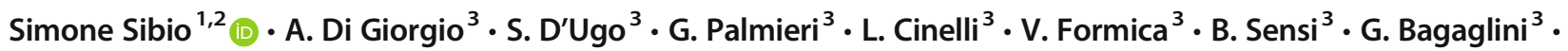 \\ S. Di Carlo ${ }^{3}$ - V. Bellato ${ }^{4} \cdot$ G. S. Sica ${ }^{3}$
}

Received: 27 November 2018 / Accepted: 13 September 2019

(C) Springer-Verlag GmbH Germany, part of Springer Nature 2019

\begin{abstract}
Aim To investigate whether differences in histotype in colon cancer correlate with clinical presentation and if they might influence oncological outcomes and survival.

Methods Data regarding colon cancer patients operated both electively or in emergency between 2009 and 2014 were retrospectively collected from a prospectively maintained database and analyzed for the purpose of this study. Rectal cancer was excluded from this analysis. Statistical univariate and multivariate analyses were performed to investigate possible significant variables influencing clinical presentation, as well as oncological outcomes and survival.

Results Data from 219 patients undergoing colorectal resection for cancer of the colon only were retrieved. One hundred seventyfour patients had an elective procedure and forty-five had an emergency colectomy. Emergency presentation was more likely to occur in mucinous $(p<0.05)$ and signet ring cell $(p<0.01)$ tumors. No definitive differences in 5-year overall (44.7\% vs. $60.6 \%$, $p=0.078)$ and disease-free $(51.2 \%$ vs. $64.4 \%, p=0.09)$ survival were found between the two groups as a whole, but the T3 emergency patients showed worse prognosis than the elective $(p<0.03)$. Lymph node invasion, laparoscopy, histology, and blood transfusions were independent variables found to influence survival. Distribution assessed for pTNM stage showed T3 cancers were more common in emergency $(p<0.01)$.

Conclusions and discussion Mucinous and signet ring cell tumors are related to emergency presentation, pT3 stage, poorest outcomes, and survival. Disease-free survival in patients who had emergency surgery for T3 colon cancer seems related to the histotype.
\end{abstract}

Keywords Colon cancer $\cdot$ Emergency $\cdot$ Elective $\cdot$ Surgery $\cdot$ Mucinous cancer

Simone Sibio

Simone.sibio@uniroma1.it

\author{
A. Di Giorgio \\ alessandra_digiorgio@yahoo.it \\ S. D’Ugo \\ dugo.stefano@gmail.com \\ G. Palmieri \\ giampiero.palmieri@uniroma2.it \\ L. Cinelli \\ lo.cinelli@gmail.com \\ V. Formica \\ vincenzo.formica@uniroma2.it \\ B. Sensi \\ brunosensi@outlook.it \\ G. Bagaglini \\ giulia.bagaglini@hotmail.it
}

\author{
S. Di Carlo \\ saradicarlo81@gmail.com \\ V. Bellato \\ vittoria.bellato@gmail.com \\ G. S. Sica \\ sigisica@gmail.com
}

1 Department of Surgery "Pietro Valdoni", Sapienza University of Rome, Viale del Policlinico 155, 00161 Rome, Italy

2 Department of Surgery "Pietro Valdoni”, Sapienza University of Rome, Via Lancisi 2, 00155 Rome, Italy

3 Department of Surgery, Tor Vergata Hospital, Tor Vergata University of Rome, Viale Oxford 81, 00133 Rome, Italy

4 Department of Surgical Sciences, Sapienza University of Rome, Viale del Policlinico 155, 00161 Rome, Italy 


\section{Introduction}

The prognosis of colon cancer (CC) is influenced by the disease stage. Survival rates are reported between 97.4 and $8.1 \%$, for early and metastatic disease [1]. Although survival rates seem to have grown during the last 40 years, in western countries, 5 -year overall survival is $60 \%$ [2]. Worldwide, emergency admission and treatment of CC patients remain a public health concern; emergency presentation is associated with advanced-stage disease, greater morbidity and mortality, higher risk of recurrence, and poorer prognosis [3-6]. A wide range of screening programs are applied to provide early diagnosis, more conservative treatment, and better survival [7]. Nevertheless, $20-32 \%$ of diagnoses are still carried out in case of advanced disease or during emergency presentation [8].

The TNM classification [9-11] is applied to CC staging. Among parameters determining stage, bowel wall infiltration (T parameter) is strongly correlated to the overall survival, since lymph node involvement, vascular invasion, and recurrence depend on it [12-17]. Emergency presentation has been associated with several social and behavioral factors as well as some clinical and biological characteristics of the tumor, as perineural invasion, TNM stage, and tumor location [3-6, 13-16].

Although mucinous histology has been regarded as not influencing survival and outcomes per se in $\mathrm{CC}$ in two recent large studies $[18,19]$, little is known about the role of histology in influencing clinical presentation, which is indeed generally regarded as a prognostic factor.

The aim of the present study was to investigate whether biological or histologic parameters influence clinical presentation for CC patients and, thus, to find possible correlations with oncological outcomes and survival.

\section{Patients and methods}

All clinical data of CC patients, referred for surgical treatment from November 2009 to November 2014, were prospectively collected. Data have been retrospectively analyzed for the purpose of the study. Patients were divided into two groups with respect to their clinical presentation: elective (EL) or emergency (EM) surgery. All patients underwent surgical treatment in a single unit. The demographic and clinical characteristics collected were as follows: age, sex, tumor location, lifestyle features such as smoke, alcohol abuse, personal or familiar history of CC, possible co-morbidities like obesity, BMI, hypertension, diabetes, dyslipidemia, other previous or synchronous neoplastic diseases, symptoms at presentation such as anemia, diarrhea, abdominal tenderness, rectal bleeding, fecal occult blood, constipation, weight loss, bowel obstruction or perforation, and neo-adjuvant chemotherapy.
Histology, pTNM stage, grading, length of specimens, surgical outcomes such as type and length of surgery, hospital stay, duration of antibiotic treatment, need for blood transfusions, time to restart of oral intake, morbidity, mortality, and 5year overall and disease-free survival were evaluated in the two settings as well. Patients underwent emergency surgery when occlusion, perforation, or severe bleeding was present on admission. Laparoscopic approach was preferred whenever feasible. Four experienced colorectal surgeons from a single unit or surgical residents under guidance performed all surgical interventions. Two senior surgeons were not keen on laparoscopic surgery and they did not participate in the surgical rotation for emergencies. Complications were defined according to the Clavien-Dindo classification [20]. Postoperative management was performed applying the "enhanced recovery after surgery" (ERAS) protocols whenever considered possible. Endoscopy and interventional radiology were occasionally employed in case of occlusion or bleeding as bridge to surgery; these patients, when subsequently operated, were considered as elective.

\section{Statistical analysis}

Possible significant variables were studied both in univariate and multivariate analyses to investigate statistical significance of each variable and together in influencing clinical presentation, oncological outcomes, and survival. Dichotomous outcomes were compared using the chi-square test and an odds ratio (OR) calculation, while a 1-way analysis of variance or a univariate linear regression with $95 \%$ confidence interval was used for continuous outcomes. Multivariate analysis (Cox proportional hazard model) was used to investigate prognostic significance of multiple independent co-variables and to control the findings for any potentially significant confounders found during univariate analysis. The 2-tailed $p$ values below 0.05 were considered statistically significant. Survival curves were created by mean of the Kaplan-Meyer method and compared using log-rank test [21].

\section{Results}

In the 5-year period of the study, 219 consecutive CC patients undergoing colorectal surgical resection were selected from a prospectively maintained database of patients with colon cancer admitted for surgery at the "minimally invasive and gastrointestinal surgical unit" of the Tor Vergata Policlinic in Rome, Italy. One hundred seventy-four patients had an elective procedure and forty-five had an emergency colectomy. The two groups had homogenous demographic characteristics; in the EM group, there was more history of alcoholic abuse and chronic constipation $(p<0.014$ and $p<0.04$ 
respectively). Regarding symptoms at presentation, abdominal tenderness was significantly more frequent in $\mathrm{EM}(p<$ 0.002 ), while the occurrence of rectal bleeding did not significantly differ between the two groups. Perforation and bowel occlusion were indeed the most frequent clinical symptoms in EM (Table 1). No patient underwent neo-adjuvant chemotherapy in the two groups.

Surgical procedures are summarized in Table 2. Three total/ subtotal colectomies were performed in patients known to have an associated inflammatory bowel disease; one or more surgical procedures (splenectomy, cholecystectomy, small bowel resection, and hepatic resection) were associated with colon resection in 9 patients ( $3 \mathrm{EM}, 6 \mathrm{EL}$ ). As for right hemicolectomy, complete mesocolic excision (CME) was undertaken in 61 out of 97 elective patients; no CME was done in emergency resections $(p<0.0001)$. Differences were found regarding the number of bowel diversions (i.e., colostomy or ileostomy): six (13.3\%) in the EM group and one $(0.6 \%)$ in the EL group $(p<0.001)$. In addition, EM patients received significantly more blood transfusion than patients in the EL

Table 1 Demographics and clinical characteristics of the study sample

\begin{tabular}{|c|c|c|c|}
\hline $\mathrm{N}(\%)$ & Emergency & Elective & $\mathrm{p}$ value \\
\hline Patients - tot. 219 & 45 & 174 & \\
\hline Mean age & 71 & 68 & 0.13 \\
\hline $\operatorname{Sex} M(\%)$ & $32(71.1)$ & $88(50.5)$ & 0.08 \\
\hline Mean BMI (range 15.4-41) & 25.2 & 25.4 & 0.2 \\
\hline Obesity BMI $\geq 30(\%)$ & $6(13.3)$ & $24(13.7)$ & 0.2 \\
\hline Diabetes mellitus & $6(13.3)$ & $25(14.3)$ & 0.18 \\
\hline Dyslipidemia & $5(11.1)$ & $27(15.5)$ & 0.09 \\
\hline Hypertension & $30(66.6)$ & 95 (54.6) & 0.07 \\
\hline History of CC & $1(2.2)$ & $6(3.4)$ & 0.12 \\
\hline Other neoplasm & $7(15.5)$ & $29(16.6)$ & 0.2 \\
\hline Family history of CC & $7(15.5)$ & $34(19.5)$ & 0.09 \\
\hline Smoke & $8(17.7)$ & $28(16.1)$ & 0.13 \\
\hline Alcohol abuse & $2(4.4)$ & $4(2.3)$ & 0.014 \\
\hline Anemia & $21(46.6)$ & $61(35.1)$ & 0.087 \\
\hline Diarrhea & $6(13.3)$ & $13(7.4)$ & 0.04 \\
\hline Constipation & $16(35.5)$ & $32(18.4)$ & 0.04 \\
\hline Rectal bleeding & $13(28.9)$ & $52(29.9)$ & 0.2 \\
\hline Abdominal tenderness/bloating & $31(68.9)$ & $37(21.3)$ & 0.02 \\
\hline Weight loss & $9(20)$ & $23(13.2)$ & 0.087 \\
\hline Fecal occult blood FOB & $2(4.4)$ & $54(31)$ & 0.01 \\
\hline \multicolumn{4}{|l|}{ Emergency presentations } \\
\hline Perforation & $9(20)$ & - & \\
\hline Occlusion & $17(37.7)$ & - & \\
\hline Other & $19(42.2)$ & & \\
\hline \multicolumn{4}{|l|}{ Cancer location } \\
\hline Left & $15(33.3)$ & $77(44.2)$ & 0.07 \\
\hline Right & $30(66.6)$ & $97(55.7)$ & \\
\hline
\end{tabular}

group did: 0.9 units of red blood cells in EM vs. 0.5 in EL $(p<0.04)$. Furthermore, the open approach and conversion rates from laparoscopy to laparotomy were both significantly more common in the EM group. Laparoscopic right hemicolectomy was more frequently performed in elective than in emergency patients $(p=0.03)$. Hartmann's procedure was far more common in emergency $(p=0.04)$. The length of surgery was slightly shorter in emergency, while hospital stay was significantly longer as compared with elective ( $p<$ 0.002). Morbidity was similar in the two samples, although minor complications requiring medical conservative treatment (Clavien-Dindo 2) were more frequent in emergency (Table 3). No significant differences were found in specimen length and number of harvested lymph nodes in the two groups (mean length of specimens, $28.9 \mathrm{~cm}$ for right hemicolectomy and $36.1 \mathrm{~cm}$ for left hemicolectomy in EL; $26.9 \mathrm{~cm}$ and $33.7 \mathrm{~cm}$ respectively in EM; mean number of harvested lymph node for right/left hemicolectomy, 19 in EL and 16 in EM groups).

Distribution of histology between mucinous and not mucinous cancers was similar in the two groups, except for G1 and stage I cancers that were mostly prevalent in EL.

Distribution assessed for pTNM stage showed that T1 and T2 tumors were mainly observed in EL while T3 cancers (with any $\mathrm{N})$ and $\mathrm{M}+$ were more common in $\mathrm{EM}(p<0.01)$. Emergency presentation was more likely to occur in the case of mucinous $(p<0.05)$ and signet ring cell $(p<0.01)$ tumors (Table 4).

Mean follow-up was 53 months (range 1-118 months). Fifty-three (15\%) patients were lost at follow-up (32 EL, 7 EM). Among the 142 elective patients in follow-up, 86 patients are alive and disease free $(60.6 \%), 19$ are alive with recurrent disease (13.3\%): 9 had liver metastases, 2 local recurrence, 6 peritoneal metastases, and 2 both liver and peritoneal recurrence. Twenty-seven patients died of cancer-related causes (19\%); ten patients died for other reasons (7.7\%). In the 38 emergency patients in regular follow-up, 17 patients are alive and disease free (44.7\%), 7 are alive with disease recurrence (18.4\%): three of them have liver metastases, 2 local recurrence on colorectal anastomosis, and two peritoneal metastases; twelve patients died of disease (31.6\%) and 2 died for other causes $(5.3 \%)$. No differences were found among groups.

Twenty (44.4\%) EM and 69 (39.6\%) EL patients had adjuvant treatment (after surgery). In the EM group, there was no significant delay in starting adjuvant treatments.

Variables found significant or close to significance in the univariate analysis (elective or emergency surgery, laparoscopic or open procedure, blood transfusions, MC or SRCC histology, $\mathrm{T}$ and $\mathrm{N}$ stages, chemotherapy, disease location, and morbidity) were matched in the multivariate analysis. Cox regression model confirmed lymph node invasion, histology, blood transfusions, and laparoscopic surgery as independent 
Table 2 Surgical procedures in the two groups

\begin{tabular}{lllll}
\hline Surgical procedure & Emergency & Elective & Tot. & $\mathrm{p}$ \\
\hline $\begin{array}{l}\text { Right/transverse colon cancer } \\
\text { Right hemicolectomy (LPS) }\end{array}$ & $28(6)$ & $97(44)$ & 127 & $\mathrm{p}=0.03(\mathrm{p}=0.02)$ \\
CME & - & 61 & $\mathrm{p}<0.0001$ \\
Total/subtotal colectomy & 2 & - & & \\
Left colon cancer & $11(8)$ & $76(50)$ & 92 & $\mathrm{p}=0.08(\mathrm{p}=0.04)$ \\
Left hemicolectomy (LPS) & 3 & $1(1)$ & \\
Hartmann procedure (LPS) & 1 & - & & \\
Total/subtotal colectomy & 1 & & & \\
Other surgical procedures & 2 & - & & \\
Splenectomy & - & 2 & & \\
Cholecystectomy & - & 3 & & \\
Hepatic resection & $6(13.3 \%)$ & $1(0.6 \%)$ & & \\
Small bowel resection & $45(14)$ & $174(95)$ & 219 & $(\mathrm{p}<0.001)$ \\
Colostomy/ileostomy (\%) & & & & \\
Tot. & & & & \\
\hline
\end{tabular}

LPS, laparoscopic; CME, complete mesocolic excision variables influencing survival, while emergency surgery was found not to influence cancer related nor overall survival (Table 5).

Survival Kaplan-Meyer curves are reported in Figs. 1, 2, 3, and 4 . There was not a clear difference $(p=0.07)$ in the 5-year overall and disease-free survival between EL and EM CC patients (Fig. 1). However, differences were found when patients were stratified for $\mathrm{pT}$ stage and patients with a pT3 tumor in the EM group had gone worst (Table 6) (Fig. 2). Moreover, mucinous or SRCC histology was found to negatively impact on both overall and disease-free survival in the EM group (Figs. 3 and 4).

\section{Discussion}

Several published studies support the intuitive observation that patients undergoing surgery for colon or rectal cancer in emergency do worse, also regarding the long-term outcome, compared with elective patients [22-26]. A recent article by Amri et al. confirmed that emergency surgery is an independent negative prognostic factor not dependent on stage at diagnosis. The authors report that several pathological factors, such as tumor biology, high-grade disease, lymph-vascular and perineural invasion, trans-mural growth and margin positivity, and worse lifestyle habits, are far more common in emergency presentation. All these factors were found responsible to influence prognosis in the Cox model [27]. Furthermore, several studies found differences in stage disease presentation and outcome among ethnic and socioeconomic groups of people, thus reflecting the importance of wider diffusion of screening programs [28-30]. On the other hand, a large and recent study by Weixler et al. on a large sample of
747 patients observed no statistical differences in survival and prognosis between emergency and elective patients who underwent surgery for colorectal cancer, after a risk-adjusted statistical analysis. The results of this study highlight the close relationship between worst oncologic outcome in emergency and tumor and patient characteristics at baseline, more than the urgent operation itself [31].

Our study analyzed a consecutive series of CC patients, treated in a single unit over a 5-year period and whose data were prospectively collected. Patients were divided into two groups depending on surgical treatment: EM and EL. Clinical and pathological data were recorded and associated with longterm outcome. The aim of the study was to find possible correlations among bio-clinical characteristics such as histology, and stage and clinical presentation. Differences in oncological outcomes and survival in the two groups under analysis were also researched. In our series, the number of patients requiring emergency surgery was in line with data of other western series [32-35]. Differences in histology and T stage were found among the two groups; mucinous histology seemed capable to influence clinical emergency presentation in stage $\mathrm{T} 3$ and it was associated with a worse oncological outcome.

The message we would like to convey has an oncological focus and potential clinical relevance: mucinous histology, although cannot be considered a negative prognostic factor per se $[18,19]$, is an element that seems to influence the clinical presentation of colon cancer. Especially in T3 tumors, we found it was associated with those cases that more frequently are seen as clinical emergency. Even if on a little sample, this finding is a novel pronouncement. Furthermore, the debate whether emergency colon surgery is associated with a worst oncological outcome is still ongoing and in fact some recent studies found that a "bridge to surgery" strategy 
Table 3 Surgical outcomes, morbidity, and mortalityunivariate analysis (chi-square test)

\begin{tabular}{|c|c|c|c|}
\hline & Emergency $(n=45)$ & Elective $(n=174)$ & $p$ \\
\hline \multicolumn{4}{|l|}{ P stage $(\%)$} \\
\hline $\mathrm{T} 1$ & $3(6.7)$ & $32(18.4)$ & \multirow{4}{*}{$<0.01$} \\
\hline $\mathrm{T} 2$ & $1(2.2)$ & $15(8.6)$ & \\
\hline $\mathrm{T} 3$ & $38(84.4)$ & $106(61)$ & \\
\hline $\mathrm{T} 4$ & $3(6.7)$ & $2112)$ & \\
\hline \multicolumn{4}{|l|}{$\mathrm{N}$} \\
\hline No & $30(66.7)$ & $103(59.2)$ & \multirow{3}{*}{0.07} \\
\hline N1 & $10(22.2)$ & $29(16.7)$ & \\
\hline $\mathrm{N} 2$ & $5(11.1)$ & $30(17.2)$ & \\
\hline \multicolumn{4}{|l|}{ M } \\
\hline M0 & $38(84.4)$ & $164(94.3)$ & \multirow[t]{2}{*}{$<0.04$} \\
\hline M1 & $7(15.6)$ & $10(5.7)$ & \\
\hline \multicolumn{4}{|l|}{ Grading } \\
\hline G1 & $3(6.7)$ & $22(12.6)$ & \multirow{3}{*}{$=0.051$} \\
\hline $\mathrm{G} 2$ & $18(40)$ & $86(49.4)$ & \\
\hline G3 & $24(53.3)$ & $66(38)$ & \\
\hline \multicolumn{4}{|l|}{ Type of surgery } \\
\hline Open & $31(68.9)$ & $68(39.1)$ & \multirow{3}{*}{$<0.04$} \\
\hline Laparoscopic & $9(20)$ & $81(46.6)$ & \\
\hline Conversion & $5(11.1)$ & $25(14.4)$ & \\
\hline Hospital stay (mean days) & 14.5 & 8.4 & $<0.002$ \\
\hline \multicolumn{4}{|l|}{ Morbidity (Clavien-Dindo) } \\
\hline 0 & $34(54.8 \%)$ & $175(63 \%)$ & \multirow{6}{*}{0.08} \\
\hline 1 & $5(8 \%)$ & $28(10 \%)$ & \\
\hline 2 & $20(32.2 \%)$ & $53(19.2 \%)$ & \\
\hline 3 & $1(1.6 \%)$ & $16(5.8 \%)$ & \\
\hline 4 & $1(1.6 \%)$ & $3(1 \%)$ & \\
\hline 5 & $1(1.6 \%)$ & $3(1 \%)$ & \\
\hline Transfusions (RBC per units) (mean) & 0.9 & 0.5 & $<0.04$ \\
\hline Length of antibiotic use (mean) & 7 days & 5 days & 0.09 \\
\hline Time to oral intake (POD) & 5 th & 4th & 0.1 \\
\hline Operative time (min) & 157 & 164 & 0.1 \\
\hline \multicolumn{4}{|l|}{ UICC stage } \\
\hline I & $8(12.9 \%)$ & $72(26.1 \%)$ & $p=0.03$ \\
\hline II & $25(40.3 \%)$ & $90(32.7 \%)$ & $p=0.12$ \\
\hline III & $21(33.8 \%)$ & $91(33 \%)$ & $p=0.3$ \\
\hline IV & $8(12.9 \%)$ & $22(8 \%)$ & $p=0.098$ \\
\hline No. of harvested lymph nodes & 13.7 & 12.7 & 0.2 \\
\hline Time to adjuvant chemo (days) & 42 & 38 & 0.1 \\
\hline Adjuvant chemo, $n(\%)$ & $20(44.4)$ & $69(39.6)$ & 0.1 \\
\hline
\end{tabular}

$P O D$, postoperative day

might provide better oncologic outcomes in T3 occluded patients [36-38]. On the base of our findings, we cannot provide any further clarification on the matter but we were able to link the clinical presentation to the histotype, tumor stage, and clinical presentation.

When patients were stratified for the $\mathrm{T}$ parameter, regardless of the involvement of the lymph nodes, EM patients with sub-serosal infiltration (T3) showed worse outcomes and poorer prognosis if compared with EL patients. This is the first study to report this observation to our knowledge. Furthermore, in our series, T3 patients, as well as being the majority $(61.4 \%)$, were also the subgroup that was more often treated in emergency. Attempts have been made to identify better the role of $\mathrm{T} 3$ subgroups on influencing survival rates 
Table 4 Correlation between mucinous and signet ring cell histology and clinical presentation in $\mathrm{T} 3$ patients and in whole sample (univariate analysis, chi-square test)

\begin{tabular}{lllll}
\hline & Emergency & Elective & Tot. & $p$ \\
\hline T3 histology & & & & \\
NMC & $27(71 \%)$ & $89(76 \%)$ & 116 & 28 \\
MC + SRCC & $11(29 \%)$ & $17(16 \%)$ & 144 & \\
Tot. & 38 & 106 & & \\
Whole sample histology & & & 164 & \\
NMC & $33(73 \%)$ & $131(75.3 \%)$ & 55 \\
MC + SRCC & $12(26.6 \%)$ & $43(24.7 \%)$ & 219 & \\
TOT. & 45 & 174 & & \\
Signet ring cell histology & and clinical presentation & - whole sample & & \\
NMC + MC & $41(91.1 \%)$ & $173(99.4 \%)$ & $214(97.7)$ & $5(2.3 \%)$ \\
SRCC & $4(8.9 \%)$ & $1(0.6 \%)$ & 219 & \\
TOT. & 45 & 174 & & $p=0.097$ \\
& Occlusion & Perforation & & \\
MC + SRCC & 3 & 3 & & \\
NMC & 22 & 8 & 11 & \\
TOT. & 25 & & & \\
\hline
\end{tabular}

$N M C$, non-mucinous cancer; $M C$, mucinous cancer; $S R C C$, signet ring cell cancer but results are misleading. Mrak et al., in a large study on 368 colorectal cancer patients, found no differences in overall and disease-free survival in four subgroups of $\mathrm{pT} 3$ patients divided according to depth of bowel wall infiltration; they found, instead, that higher pT3 subgroups had a significant influence on lymph node involvement and vessel invasion in rectal cancer patients [39]. We focused our search on factors able to explain our results: histology and histologic subtypes seem to be important factors in determining clinical presentation and disease stage at baseline. Studies demonstrated how mucinous and signet ring cell (SRCC) carcinomas are often associated with a more advanced stage at diagnosis, poorer adjuvant treatment response, and a worse prognosis [40-42]. As a matter of fact, mucinous tumors and SRCC histology have a more aggressive biological behavior; both types tend to affect younger patients and are often associated with early peritoneal spread and higher recurrence rates. In our series, EM T3 patients presented a quite threefold higher incidence of mucinous and SRCC when compared with the T3 CC in the EL group. Given that the most frequent presentation of colon tumor is in stage T3 and given that the number of emergency admission is also more frequent for T3 tumors, this observation might be of some importance. In our series, if considering the whole sample, emergency presentation per se did not appear to be related to worse outcome and poorer prognosis. However, the T3 subgroup of patients treated in emergency showed a different behavior as compared with the elective ones. A possible reason could be found in the higher rate of mucinous and signet ring cell tumors in this subset of patients. The Cox regression model confirmed mucinous and signet ring cell histology among independent prognostic factors influencing survival. This observation is of some relevance if we look at the high rate of signet ring cell tumors among emergency T3 mucinous patients as compared with the rest of the sample $(p<0.001)$. However, a clear explanation for the more aggressive behavior of these histology types is not yet available; SRCCs are reported to rise from the flat colic mucosa and not to follow the classic adenocarcinoma sequence in their development. Most of these SRCCs are present in emergency because of perforation or occlusion; both these mechanisms are known to increase the peritoneal seeding and thus to worsen the prognosis. Stool DNA testing is being studied to find a diagnostic tool for early detection of these tumors [43] as well as the use of adhesion molecule testing for detection of early recurrence $[44,45]$ in order to better clarify the role of this histologic subtype in determining long-term survival.

As secondary finding, we found that in the multivariate analysis, disease-free and overall survival were similar for both the EM and the EL groups, and so were the mortality rate and surgical outcomes. However, the difference in survival between emergency and elective surgery was close to significance ( $p=0.07$ ) and the numbers of the two groups under analysis (142 EL vs. 38 EM completed the whole follow-up) are too small to draw definitive conclusions.

The quality of oncologic resection is supposed to be one of the causes of the worse outcomes of the emergency colorectal cancer surgery although recent studies showed that a correct oncologic resection in terms of harvested lymph nodes and wide margins could be easily achieved also in emergency in expert hands [46, 47].

In our retrospective analysis, we had to consider different surgical approaches and none of the patients operated on emergency had a CME. However, we found no differences in the quality of the specimens (length or number of harvested 
Table 5 Univariate and multivariate analyses for prognostic factors

\begin{tabular}{|c|c|c|c|c|}
\hline Variables & 5 -year OS (\%) & $p$ value & 5 -year DFS (\%) & $p$ value \\
\hline Age & & 0.2 & & 0.2 \\
\hline$<65$ years & 60.4 & & 56.5 & \\
\hline$>65$ years & 58.3 & & 52.7 & \\
\hline Cancer location & & 0.059 & & 0.1 \\
\hline Left colon & 66.5 & & 58.3 & \\
\hline Right colon & 54.6 & & 51.2 & \\
\hline Type of surgery & & 0.078 & & 0.09 \\
\hline Emergency & 44.7 & & 51.2 & \\
\hline Elective & 60.6 & & 64.4 & \\
\hline Type of procedure & & 0.057 & & 0.06 \\
\hline Open & 56.3 & & 53.2 & \\
\hline Laparoscopic & 64.5 & & 63.1 & \\
\hline T stage & & 0.02 & & 0.02 \\
\hline $\mathrm{T} 1-2$ & 80.3 & & 78.3 & \\
\hline $\mathrm{T} 3-4$ & 49.7 & & 45.4 & \\
\hline N stage & & 0.03 & & 0.03 \\
\hline $\mathrm{N}+$ & 31.8 & & 30.2 & \\
\hline $\mathrm{N}-$ & 61.2 & & 58.3 & \\
\hline Morbidity (Clavien-Dindo) & & 0.04 & & 0.03 \\
\hline $0-2$ & 65.1 & & 57.8 & \\
\hline $3-4$ & 47.2 & & 42.8 & \\
\hline Blood transfusions & & 0.05 & & 0.05 \\
\hline No & 64.2 & & 54.7 & \\
\hline Yes & 50.2 & & 43.9 & \\
\hline Histology & & 0.01 & & 0.02 \\
\hline $\mathrm{MC} / \mathrm{SRCC}$ & 32.6 & & 29.2 & \\
\hline $\mathrm{NMC}$ & 64.4 & & 58.4 & \\
\hline Adjuvant chemotherapy & & 0.054 & & 0.055 \\
\hline Yes & 42.1 & & 39.2 & \\
\hline \multirow[t]{2}{*}{ No } & 63.7 & & 60.6 & \\
\hline & Wald & Exp & $95 \%$ CI-Exp & $p$ value \\
\hline Elective vs. emergency & 5.435 & 1.876 & $1.142-5.213$ & 0.078 \\
\hline chemotherapy & 0.332 & 1.112 & $0.549-2.245$ & 0.45 \\
\hline Right colon & 2.121 & 18.910 & $0.365-1021.091$ & 0.12 \\
\hline Left colon & 1.961 & 16.777 & $0.324-868.421$ & 0.16 \\
\hline $\mathrm{N}+$ & 11.432 & 0.123 & $0.131-0.543$ & 0.01 \\
\hline Lps/open & 7.121 & 0.333 & $0.112-0.803$ & 0.02 \\
\hline Blood transfusions & 5.432 & 0.320 & $0.171-0.842$ & 0.02 \\
\hline Clavien-Dindo grade $3 / 4$ & 1.60 & 0.821 & $0.259-2.380$ & 0.99 \\
\hline $\mathrm{pT}$ & 2.576 & 0.661 & $0.251-1.743$ & 0.45 \\
\hline $\mathrm{MC}$ or SRCC histology & 7.123 & 0.278 & $0.212-1.232$ & 0.03 \\
\hline
\end{tabular}

$M C$, mucinous; $S R C C$, signet ring cell cancer lymph nodes). Furthermore, as a matter of fact, there is no randomized trial demonstrating prognostic advantages of the CME over a standard right colectomy with high tie of the vessels [48]. It is likely that surgeons operating in emergency preferred not to prolong the length of surgery by performing a surgical procedure whose oncological benefits are unclear. Some recent papers proposed a new classification of surgical specimens and anatomical borders of CME and a trial evaluating oncological advantages is ongoing [49-51]. Studies have reported oncologic advantage and same morbidity for CME in stage I-III right CC patients operated by experienced surgeons [52-54]. This is 
Survival Plot

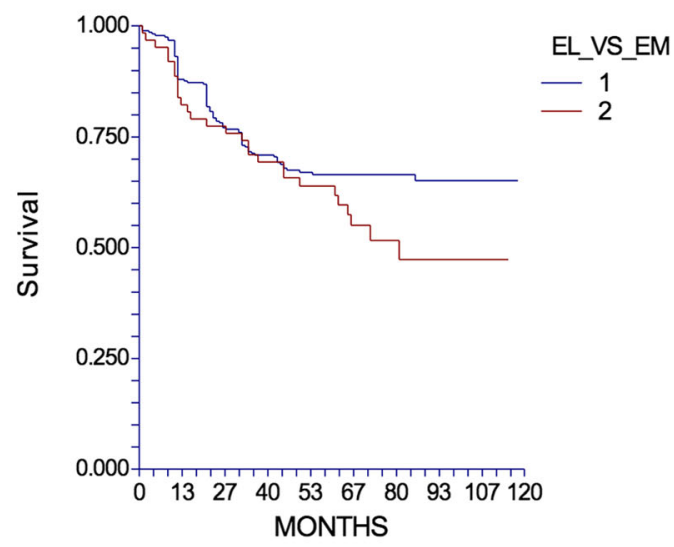

Overall survival $\mathrm{p}=0.078$
Survival Plot

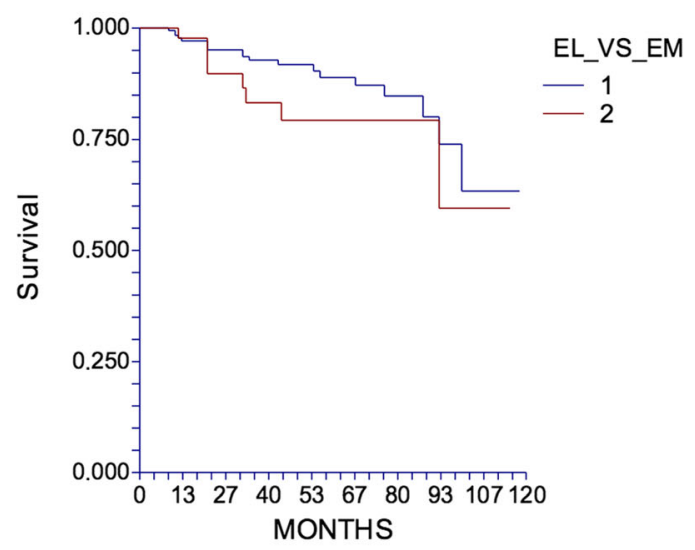

Disease free survival $\mathrm{p}=0.19$

\section{$1=$ elective patients \\ $2=$ emergency patients}

Fig. 1 Overall and disease-free survival curves of the two groups of patients (elective vs. emergency)

the reason why in our more recent EL cases, we are now undertaken CME. However, at the present, we could not find any differences in the quality of the resected specimens nor in the short-term complication rates.

In both groups, when chemotherapy was required, there was a timely start of the adjuvant treatment, even though hospital stay was slightly longer in EM. A possible explanation for this finding can be seen in the clinical setting of a medium/high-volume center and a specialist colorectal unit providing a dedicated and fully integrated specialized team.

Data from the present study were prospectively collected; more than 200 patients with CC were included and treated in a single specialized referral unit for surgical disease of the colon

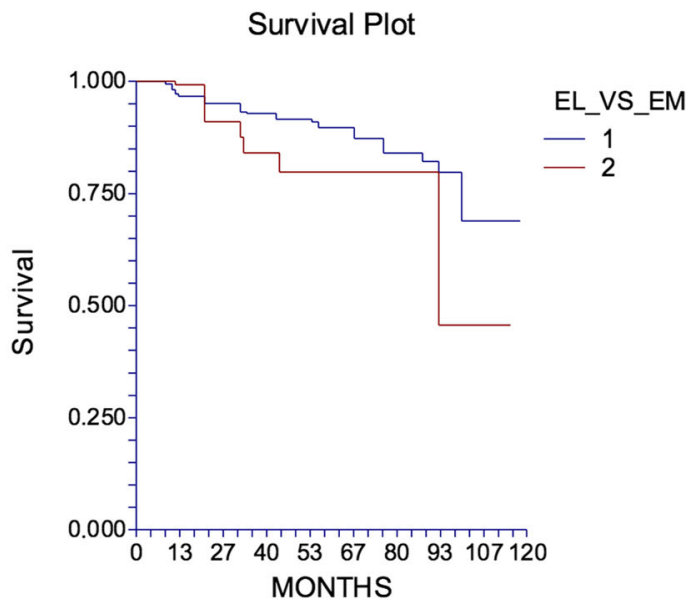

Overall survival $\mathrm{p}=0.001$

Disease free survival $\mathrm{p}=0.002$

\section{$1=$ elective patients $2=$ emergency patients}

Fig. 2 Overall and disease-free survival curves in pT3 patients in the two groups (elective vs. emergency) 


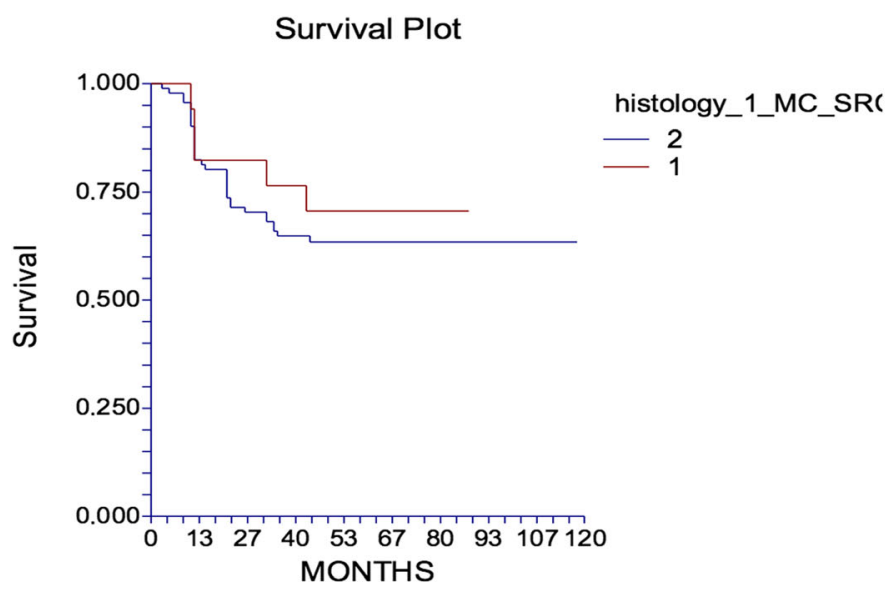

\section{Overall survival $\mathrm{p}=0.5$}

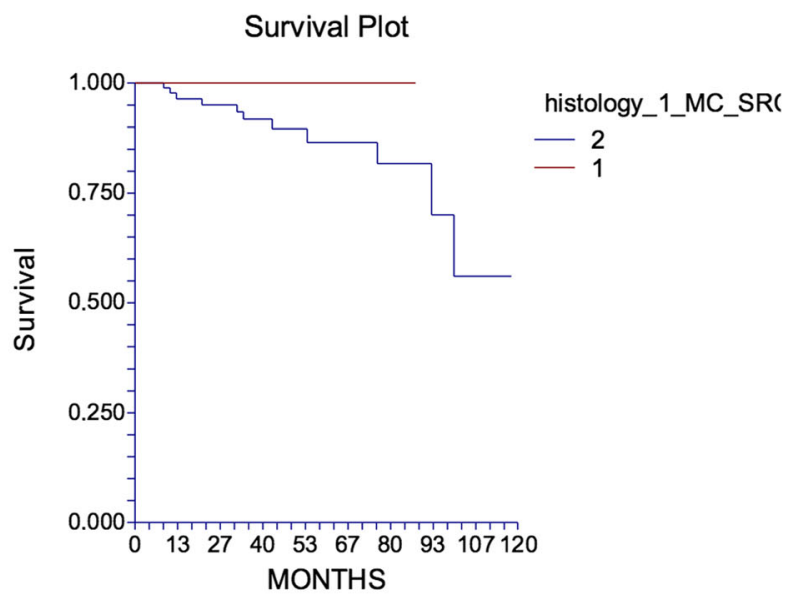

Disease free survival $\mathrm{p}=0.15$

\section{$1=$ mucinous histology $2=$ non mucinous histology}

Fig. 3 Overall and disease-free survival curves for mucinous vs. non-mucinous histology in elective patients

and rectum over 5 years. Histology was performed and reviewed at the same university laboratory from two dedicated pathologists. Patients were discussed at our multidisciplinary meeting and adherence to follow-up was good. The results from this study suggest that mucinous and SRCC histology might play a role in determining clinical presentation in pT3 colon cancer patients presenting in emergency.

Two large register-based population studies, one by Tarantino et al. and the other by Warschkow et al. [18, 19], focused their attention on mucinous histology respectively in rectal and colon cancers, concluding that this histology appears to not negatively impact survival and, hence, no different treatment strategy or follow-up should be considered for these patients.

Looking at the rough data, they found that a mucinous histology is indeed more frequent in T3 stages (62.2\%) if compared with non-mucinous $(57.1 \%)$. The main difference of our study is that we did take into consideration also the clinical presentation. Mucinous histology influences clinical presentation and it is more frequent in

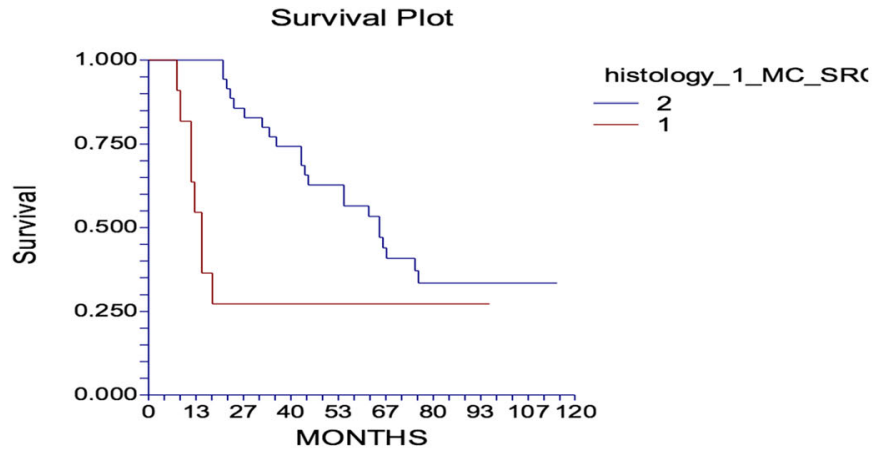

Overall survival $\mathrm{p}=0.03$

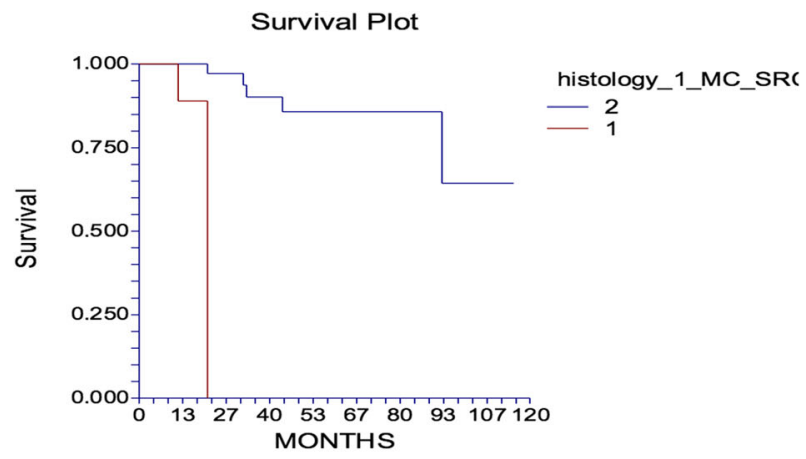

Disease free survival $\mathrm{p}=0.001$

\section{$1=$ mucinous histology $2=$ non mucinous histology}

Fig. 4 Overall and disease-free survival curves for mucinous vs. non-mucinous histology in emergency patients 
Table 6 Five-year overall and disease-free survival in whole sample and stratified for $\mathrm{T}$ stage

\begin{tabular}{|c|c|c|c|}
\hline & Emergency & Elective & $p$ \\
\hline O.S. & $44.7 \%$ & $60.6 \%$ & $p=0.078$ \\
\hline \multicolumn{4}{|c|}{ O.S. stratified for $T$} \\
\hline pT1 & $94.4 \%$ & $98.7 \%$ & $p=0.2$ \\
\hline pT2 & $59.2 \%$ & $71.1 \%$ & $p=0.066$ \\
\hline pT3 & $24.2 \%$ & $61.8 \%$ & $p=0.001$ \\
\hline pT4 & $7.9 \%$ & $11.8 \%$ & $p=0.088$ \\
\hline D.F.S. & $51.2 \%$ & $64.4 \%$ & $p=0.09$ \\
\hline D.F.S. (pT3) & $26.2 \%$ & $62.4 \%$ & $p=0.002$ \\
\hline
\end{tabular}

patients with T3 stage that have undergone emergency surgery; actually, the same group of patients shows the poorest outcomes. A collateral finding of our study confirms that in high-volume specialized referral centers, emergency presentation per se should not affect surgical outcomes and survival. Major biases of our study are the retrospective nature of the analysis, even though on a prospective collected database, and the relatively small samples and the subsequent little number of mucinous and SRCC, although in line with commonly reported rates. Nevertheless, considering our results, a correlation between mucinous histotype and emergency presentation for $\mathrm{CC}$ leading to worse oncologic outcomes in $\mathrm{T} 3 \mathrm{mu}-$ cinous cancers is conceivable.

\section{Conclusions}

The most common $\mathrm{T}$ stage found in $\mathrm{CC}$ patients undergoing surgery in emergency is pT3. Mucinous and signet ring cell tumors are threefold more frequent in emergency in this subgroup of patients. In multivariate analysis, these tumors seem to be associated with poorer outcomes and prognosis. According to our results, it seems possible that pT3 EM tumors do have worse prognosis because they are more commonly mucinous and/or SRCC.

\section{Compliance with ethical standards}

Conflict of interest The authors declare that they have no conflict of interest.

Ethical approval All procedures performed in studies involving human participants were in accordance with the ethical standards of the institutional and/or national research committee and with the 1964 Helsinki declaration and its later amendments or comparable ethical standards.

Informed consent Informed consent was obtained from all individual participants included in the study.

\section{References}

1. Gunderson LL, Jessup JM, Sargent DJ, Greene FL, Stewart AK (2010) Categorization for colon cancer based on national survival outcomes data. J Clin Oncol 28(2):264-271

2. Brenner H, Bouvier AM (2012) Foshi R et al and the EUROCARE GROUP: Progress in colorectal cancer survival in Europe from the late 1980's and the early 21 st century: the EUROCARE study. Int J Cancer 13(7):1649-1658

3. Aquina CT, Becerra AZ, Xu Z et al (2017) Nonelective colon cancer resection: a continued public health concern. Surg. 161(6): $1609-1618$

4. Oliphant R, Mansouri D, Nicholson GA, McMillan D, Horgan PG, Morrison DS, West of Scotland Colorectal Cancer Managed Clinical Network (2014) Emergency presentation of node negative colorectal cancer treated with curative surgery is associated with poorer short and longer term survival. Int J Color Dis 29(5):591598

5. Brannstrom F, Gunnarson U (2016) Risk factors for local recurrence after emergency resection for colon cancer: scenario in Sweden. Dig Surg 33(6):503-508

6. Wanis KN, Ott M, Van Koughnett JAM et al (2018) Long term oncological outcomes following emergency resection of colon cancer. Int J Color Dis 33(11):1525-1532

7. Siegel R, Ma J, Zou Z, Jemal A (2014) Cancer statistics, 2014. CA Cancer J Clin 64:9-29

8. Ansaloni L, Andersson RE, Bazzoli F et al (2010) Guidelines in the management of obstructing cancer of the left colon: consensus conference of the world society of emergency surgery (WSES) and peritoneum and surgery (PnS) society. World J Emerg Surg 5:29

9. Dukes CE (1932) The classification of cancer of the rectum. J Pathol Bacteriol 35:323-332

10. Astler VB, Coller FA (1954) The prognostic significance of direct extension of carcinoma of the colon and rectum. Ann Surg 139: $846-852$

11. Hutter RV (1987) At last-worldwide agreement on the staging of cancer. Arch Surg 122:1235-1239

12. Merkel S, Mansmann U, Papadopoulos T, Wittekind C, Hohenberger W, Hermanek P (2001) The prognostic inhomogeneity of colorectal carcinoma stage III. A proposal for subdivision of stage III. Cancer 92:2754-2759

13. Miyoshi M, Ueno H, Hashiguchi Y, Mochizuki H, Talbot IC (2006) Extent of mesorectal tumor invasion as a prognostic factor after curative surgery for T3 rectal cancer patients. Ann Surg 243:492498

14. Willett CG, Badizadegan K, Ancukiewicz M, Shellito PC (1999) Prognostic factors in T3 N0 rectal cancer: do all patients require postoperative pelvic irradiation and chemotherapy? Dis Colon Rectum 42:167-173

15. Burdy G, Panis Y, Alves A, Nemeth J, Lavergne-Slove A, Valleur P (2001) Identifying patients with T3-T4 node-negative colon cancer at high risk of recurrence. Dis Colon Rectum 44:1682-1688

16. Tsai HL, Cheng KI, Lu CY, Kuo CH, Ma CJ, Wu JY, Chai CY, Hsieh JS, Wang JY (2008) Prognostic significance of depth of invasion, vascular invasion and numbers of lymph node retrievals in combination for patients with stage II colorectal cancer undergoing radical resection. J Surg Oncol 97:383-387

17. Compton CC, Fielding LP, Burgart LJ, et al (2000) Prognostic factors in colo-rectal cancer. College of American Pathologists Consensus Statement 1999. Arch Pathol Lab; ed; 124: 979-994.

18. Tarantino I, Huttner F, Warshkow R et al (2016) Prognostic relevance of mucinous subtype in a population-based propensity score analysis of 40.083 rectal cancer patients. Ann Surg Oncol 23:15761586 
19. Warschkow R, Tarantino I, Huttner F, Schmied BM, Guller U, Diener MK, Ulrich A (2016) Predictive value of mucinous histology in colon cancer: a population-based, propensity score matched analysis. Br J Cancer 114:1027-1032

20. Dindo D, Demartines N, Clavien PA (2004) Classification of surgical complications: a new proposal with evaluation in a cohort of 6336 patients and results of a survey. Ann Surg 240:205-213

21. Kaplan EL, Meier P (1958) Nonparametric estimation from incomplete observations. J Amer Statist Assn 53:457-481

22. Scott NA, Jeacock J, Kingston RD (1995) Risk factors in patients presenting as an emergency with colorectal cancer. Br J Surg 82: 321-323

23. Porta M, Fernandez E, Belloc J, Malats N, Gallén M, Alonso J (1998) Emergency admission for cancer: a matter of survival? Br J Cancer 77:477-484

24. Biondo S, Marti-Rague J, Kreisler E, Pares D, Martin A, Navarro M et al (2005) Am J Surg 189:377-383

25. Xu Z, Becerra AZ, Aquina CT, Hensley BJ, Justiniano CF, Boodry C, Swanger AA, Arsalanizadeh R, Noyes K, Monson JR, Fleming FJ (2017) Emergent colectomy is independently associated with decreased long-term overall survival in colon cancer patients. J Gastrointest Surg 21:543-553

26. Ng HJ, Yule M, Twoon M, Binnie NR, Aly EH (2015) Current outcomes of emergency large bowel surgery. Ann R Coll Surg Engl 97(2):151-156

27. Amri R, Sc. M, Bordeianou LG, Sylla P, Berger DL (2015) Colon cancer surgery following emergency presentation: effects on admission and stage-adjusted outcomes. Am J Surg 209:246-253

28. Siegel R, Ward E, Brawley O, Jemal H (2011) Cancer statistics 2011: the impact of eliminating socioeconomic and radical disparities on premature cancer deaths. CA Cancer J Clin 61:212-236

29. Ward EE, Jemal AA, Cokkinides VV et al (2004) Cancer disparities by race/ethnicity and socioeconomic status. CA Cancer J Clin 54: 78-93

30. Amri R, Stronks K, Bordeianou LG et al (2014) Gender and ethnic disparities in colon cancer presentation and outcomes in a US universal healthcare setting. J Surg Oncol 109:645-651

31. Weixler B, Warschkow R, Ramser M et al (2016) Urgent surgery after emergency presentation for colorectal cancer has no impact on overall and disease free survival: a propensity score analysis. BMC Cancer 16:208

32. Merkel S, Meyer C, Papadopoulos T, Meyer T, Hohenberger W (2007) Urgent surgery in colon carcinoma. Zentralbl Chir 132(1): $16-25$

33. Cuffy M, Abir F, Audisio RA (2004) Colorectal cancer presenting as surgical emergencies. Surg Oncol 13:149-157

34. Anderson JH, Hole D, McArdle CS (1992) Elective VS emergency surgery for patients with colorectal cancer. Br J Surg 79(7):706-709

35. Smothers L, Hynan L, Fleming J et al (2003) Emergency surgery for colon carcinoma. Dis Colon Rectum 46:24-30

36. Amelung FJ, Consten ECJ, Siersema PD, Tanis PJ (2016) A population-based analysis of three treatment modalities for malignant obstruction of the proximal colon: acute resection versus stent or stoma as a bridge to surgery. Ann Surg Oncol 23(11):3660-3668

37. Lara-Romero C, Vilches Á, Caunedo-Álvarez Á, HerguetaDelgado P, Lavín-Castejón I, Andrade-Bellido R, AlcaínMartínez G (2019) Better recurrence-free survival after stent bridge to surgery compared to emergency surgery for obstructive leftsided colonic cancer in patients with stage III status of the American Joint Committee on Cancer (AJCC): a bicentric retrospective study. Int J Color Dis 34(7):1241-1250

38. Amelung FJ, Borstlap WAA (2019) Consten ECJet al.: Dutch Snapshot Research Group. Propensity score-matched analysis of oncological outcome between stent as bridge to surgery and emergency resection in patients with malignant left-sided colonic obstruction. Br J Surg 106(8):1075-1086
39. Mrak K, Jagoditsch M (2011) Leibl Set al.: Influence of pT3 subgroups on outcome of R0-resected colorectal tumors. South Med J 104:722-730

40. Kang H, O’Connell JB (2005) Maggard Ma, et al.: A 10-year outcomes evaluation of mucinous and signet-ring cell carcinoma of the colon and rectum. Dis Colon Rectum 48:1161-1168

41. Sasaki S, Masaki T, Umetani N, Futakawa N, Ando H, Muto T (1998) Characteristics in primary signet-ring cell carcinoma of the colorectum, from clinicopathological observations. Jpn J Clin Oncol 28:202-206

42. Thota R, Fang X, Subbiah S (2014) Clinicopathological features and survival outcomes of primary signet-ring cell and mucinous adenocarcinoma of the colon: retrospective analysis of VACCR database. J Gastrointest Oncol 5:18-24

43. Imperiale TF, Ransohoff DF, Itzkowitz SH, Turnbull BA, Ross ME, Colorectal Cancer Study Group (2004) Fecal DNA versus fecal occult blood for colorectal-cancer screening in an average-risk population. N Engl J Med 351:2704-2714

44. Sica GS, Fiorani C, Stolfi C, Monteleone G, Candi E, Amelio I, Catani V, Sibio S, Divizia A, Tema G, Iaculli E, Gaspari AL (2015 May 30) Peritoneal expression of matrilysin helps identify early post-operative recurrence of colorectal cancer. Oncotarget. 6(15): 13402-13415

45. Sibio S, Fiorani C, Stolfi C, Divizia A, Pezzuto R, Montagnese F, Bagaglini G, Sammartino P, Sica GS (2015) Detection methods and clinical significance of free peritoneal tumor cells found during colorectal cancer surgery. World J Gastrointest Surg 7(9):178-184

46. Baer C, Menon R, Bastawrous S (2017) Bastawrous A: emergency presentation of colorectal cancer. Surg Clin North Am 97(3):529-545

47. Teixeira F, Hiroshi EH, Ushinohama AZ et al (2015) Can we respect the principles of oncologic resection in an emergency surgery to treat colon cancer? World J Emerg Surg 10:5

48. Wang C, Gao Z, Shen K, Shen Z, Jiang K, Liang B, Yin M, Yang X, Wang S, Ye Y (2017) Safety, quality and effect of complete mesocolic excision vs non-complete mesocolic excision in patients with colon cancer: a systemic review and meta-analysis. Color Dis 19(11):962-972

49. Benz S, Tam Y, Tannapfel A et al (2016) The uncinate process first approach: a novel technique for laparoscopic right hemicolectomy with complete mesocolic excision. Eurg Endosc 30:1930-1937

50. Benz S, Stricker I, Tam Y et al (2017) CME or traditional surgery for right-sided colon cancer? Protocol of a registry-based multicenter prospective non-randomized trial (RESECTAT trial). Coloproctology (39):184-189

51. Benz S, Tannapfel A, Tam Y, Grünenwald A, Vollmer S, Stricker I (2019) Proposal of a new classification system for complete mesocolic excision in right-sided colon cancer. Tech Coloproctology (23):251-257

52. Kim NK, Kim YW, Han YD, Cho MS, Hur H, Min BS, Lee KY (2016) Complete mesocolic excision and central vascular ligation for colon cancer: principle, anatomy, surgical technique, and outcomes. Surg Oncol 25(3):252-262

53. Bertelsen CA, Neuenschwander AU, Jansen JE, Wilhelmsen M, Kirkegaard-Klitbo A, Tenma JR, Bols B, Ingeholm P, Rasmussen LA, Jepsen LV, Iversen ER, Kristensen B, Gögenur I, Danish Colorectal Cancer Group (2015) Disease-free survival after complete mesocolic excision compared with conventional colon cancer surgery: a retrospective, population-based study. Lancet Oncol 16: $161-168$

54. Negoi I, Beuran M, Hostiuc S et al (2018) Complete mesocolic excision for colon cancer is technically challenging but the most oncological appealing. Transl Gastroenterol Hepatol 3:79

Publisher's note Springer Nature remains neutral with regard to jurisdictional claims in published maps and institutional affiliations. 